\title{
OBVIEDADES NÃO ÓBVIAS DA EDUCAÇÃO: ESCOLA PÚBLICA
}

\author{
OBVIEDADES NO OBVIAS DE LA EDUCACIÓN: ESCUELA PÚBLICA
}

NON-OBVIOUS TRUISMS OF EDUCATION: PUBLIC SCHOOL

\author{
Pedro DEMO ${ }^{1}$ \\ Renan Antônio da SILVA ${ }^{2}$
}

RESUMO: Desenvolvimento não é um aceno aberto que, mesmo tendo motivações/pressões externas, precisa ser resolvido de dentro para fora, com devida autoria. Hoje não existe qualquer chance de um país tentar alguma alternativa de política econômica que se contraponha ao liberalismo, mesmo não sendo marxista ou similar. O liberalismo é camisa de força violenta, mesmo tendo na etimologia a noção de liberdade como essencial. Não simplifiquemos as coisas, porém. Quando observamos em países africanos que moças são mutiladas genitalmente por razões religiosas, o ímpeto é defendê-las, por ser a sexualidade própria direito inalienável. Quem acredita que, mesmo sendo direitos humanos dotados de validade relativa (não relativista), é o caso condenar tais práticas mutiladoras, pois humanos não podem ser desfigurados truculentamente, entra numa seara complexa, como é interferir na educação dos filhos, para evitar que meninas sejam domesticadas como serviçais dos homens. Em qualquer caso, porém, precisamos preferir abordagens de convencimento, embora se possa ou deva admitir até mesmo intervenção para impedir truculências desse porte.

PALAVRAS-CHAVE: Pesquisa. Ensino e aprendizagem. Psicologia.

RESUMEN: El desarrollo no es un asentimiento abierto que, incluso con motivaciones/presiones externas, debe ser resuelto de adentro hacia afuera, con la debida autoría. Hoy en día no hay posibilidad de que un país intente ninguna alternativa de política económica que se oponga al liberalismo, aunque no sea marxista o similar. El liberalismo es una camisa de fuerza violenta, aunque tiene en la etimología la noción de libertad como esencial. Sin embargo, no simplifiquemos las cosas. Cuando observamos en los países africanos que las niñas son mutiladas genitalmente por razones religiosas, el impulso es para defenderlas, porque la sexualidad en sí es un derecho inalienable. Quienes creen que, aunque los derechos humanos están dotados de una validez relativa (no relativista), es preciso condenar esas prácticas de mutilación, porque los seres humanos no pueden ser truculentamente desfigurados, sino que entran en una esfera compleja, como la de interferir en la educación de los niños, para impedir que las niñas sean domesticadas como sirvientas de los hombres. En cualquier caso, sin embargo, hay que preferir los enfoques convincentes,

\footnotetext{
1 Universidade de Brasília (UnB), Brasília - DF - Brasil. Professor Emérito. Doutor em Sociologia pela Universidade do Sarre - Alemanha. Bolsista Produtividade 1B CNPq. ORCID: https://orcid.org/0000-0002-55142781.E-mail: lepp@rc.unesp.bre

${ }^{2}$ Centro Universitário do Sul de Minas (UNIS), Varginha - MG - Brasil. Pesquisador Titular no Departamento de Pesquisa. Doutor em Educação Escolar (UNESP). ORCID: https://orcid.org/0000-0003-1171-217X. E-mail: r.silva@unesp.br
} 
aunque se puede o incluso se debe admitir la intervención para evitar truculencias de esta magnitud.

PALABRAS CLAVE: Investigación. Enseñar y aprender. Psicología.

ABSTRACT: Development is not an open nod that, even having external motivations/pressions, needs to be solved from the inside out, with due authorship. Today there is no chance for a country to try any economic policy alternative that opposes liberalism, even if it is not Marxist or similar. Liberalism is a violent straitjacket, even if the notion of freedom is essential in etymology. Let us not simplify things, however. When we observe in African countries that girls are genitally mutilated for religious reasons, the impulse is to defend them, because sexuality itself is an inalienable right. Those who believe that even though human rights are endowed with relative (non-relativistic) validity, it is the case to condemn such mutilation practices, because humans cannot be truculently disfigured enters into a complex area, such as interfering with the education of children, to prevent girls from being domesticated as servants of men. In any case, however, we must prefer convincing approaches, although one can or should even admit intervention to prevent truculences of this magnitude.

KEYWORDS: Research. Teaching and learning. Psychology.

\section{Introdução}

"Escola Pública" é um capítulo superlativo da educação, ecoando grandes batalhas pela democracia e república, pelo welfare state europeu, embates contra o liberalismo econômico privatista, conquistas sindicais (trabalhadores associados), em busca de uma sociedade igualitária, na qual todos pudessem ter alguma chance de prosperar economicamente e viver qualidade de vida digna. Não cabe neste texto sucinto e introdutório. Farei aqui um apanhado inicial da questão, bem mais abrangente, mas ainda apenas introdutório, comparado ao texto da Wikipédia. A escola pública tem vínculo direto com os direitos humanos, representando o desiderato do acesso universal à educação, como alavanca que deveria estar disponível sem reservas ou supremacias/privilégios, para que os marginalizados encontrem, nesta entidade democrática e republicana, uma possível chance de melhorar de vida em todos os sentidos, não só econômico. No welfare state, mesmo dentro do liberalismo, cristalizou-se a ideia de que educação não se compra, nem se vende, sendo direito inalienável de todos. Por oferecer uma escola pública de qualidade elevada, o welfare state conseguiu outro feito importante: evitar a privatização da educação básica e até mesmo da educação superior, o que exige aportes enormes de financiamento público, implicando estruturação igualitária incisiva, por exemplo, na taxação de ingressos e riqueza. Este modelo, porém, permaneceu apenas em alguns países, em geral menos por questões democráticas, republicanas e éticas, mas pela expectativa de que educação 
básica de qualidade tem forte impacto na competitividade e produtividade, intento acolhido em tom maior no PISA e outras instâncias de avaliação externa, mesmo instrucionistas despropositadamente (ZHAO, 2018; 2014; DEMO, 2020).

Em parte, isto indica que uma etapa sombria foi superada: não há mais interesse em que a população se mantenha analfabeta, desqualificada, porque isto atrasa a economia. Prosperidade não rima com analfabetismo, como rimava no início do século passado com a escola atrelada ao fordismo, parodiado flagrantemente nos "Tempos Modernos" de Chaplin 3 . No entanto, persiste outro efeito sombrio que Foucault denominou docilização dos corpos (1977), hoje intensamente buscado no capitalismo cognitivo, na tal "empregabilidade" (o trabalhador precisa estar incansavelmente atualizado para trabalhar, embora o sistema produtivo não tenha qualquer compromisso de oferecer emprego) (FUMAGALLI et al., 2019; RINDERMANN, 2018; MILANOVIC, 2019; PIKETTY, 2020). Mesmo quando se fala, empolgadamente em geral, de espírito crítico para ser empregado na empresa do capitalismo cognitivo, a habilidade crítica não inclui questionar o sistema produtivo; muito ao contrário, comparece como aporte à competitividade e produtividade. A imagem é do trabalhador bem formado, bem comportado, estudioso, mas subserviente, que se desenha tão ostensivamente nos sistemas asiáticos de ensino (ZHAO et al., 2019).

\section{Ambiguidades de uma ideia iluminada}

Por ser educação uma referência social sempre ambígua, em grande parte por fazer parte de estruturas mais amplas de poder e ser, ela mesma, uma estrutura de poder, nem sempre entrega o que dela se espera, por vezes até faz o avesso. É uma das ideias mais civilizatórias da saga humana, mas para que tenha a qualidade necessária, muitas condições precisam ser preenchidas. Demoramos milênios para entender que alfabetização é direito fundamental. Até ao início da era moderna, alfabetizados eram poucos e o acesso à alfabetização escasso. A imprensa trouxe outra fase neste cenário, mas o passo mais importante foi a disseminação da escola pública, no contexto de um esforço coletivo que o Estado deveria conduzir e financiar (MANGUEL, 1996). Tais avanços foram possibilitados em meio a embates monumentais sobre quem pode participar na sociedade e na economia, na cultura, na política, cenários em geral reservados aos "patriarcas" endinheirados. Também nesta dimensão, educação como alfabetização sempre teve pretensões libertárias, cujo protótipo mais declamado é de "ler a

${ }^{3}$ Disponível em: https://www.youtube.com/watch?v=XFXg7nEa7vQ. Acesso em: 10 set. 2020. 
realidade" (FREIRE, 1989). Os grilhões da ignorância sempre foram comparados aos grilhões de exclusão socioeconômica, embora se tratasse de dois níveis diferentes, mas entrelaçados, da realidade: pobreza política e socioeconômica (DEMO, 2007). Educação tem condição menos visível de enfrentar a exclusão socioeconômica, embora possa ser instrumentação poderosa de preparação para o trabalho, mas tem capacidade mais efetiva de combater a exclusão política através de processos formativos que constituem sujeitos capazes de história própria individual e coletiva. Não faz isso linearmente, porque educação não é dinâmica linear; é bem complexa, podendo, mais tendencialmente privilegiar ainda mais os privilegiados, sem, porém, perder a potencialidade de ancorar processos emancipatórios reais. De modo geral, conceitos como da "aprendizagem transformadora", puxados, por exemplo, por Mezirow e colegas (MEZIROW, 2000; MEZIROW; TAYLOR, 2009; MEZIROW; ASSOCIATES, 2000; TAYLOR; CRANTON, 2012), em contexto freireano declarado, fizeram época, em especial nos Estados Unidos, sugerindo que o processo de aprendizagem, quando profundamente autoral, é potencialmente transformador.

O desafio é trazer este potencial transformador para a escola pública. Esta é uma empreitada extremamente complexa, porque acarreta um concerto difícil entre muitas e enormes iniciativas, níveis de governo, preparação dos profissionais e instituições, gestão continuada da escolarização e de seus resultados, legislações entrelaçadas e superpostas, obrigatoriedades e condições em geral pouco favoráveis das populações mais marginalizadas. Escola pública, assim, tornou-se lugar comum em praticamente todos os países, mas sob a pecha tendencial de coisa pobre para o pobre. Um punhado de países mantém escolas públicas de alto padrão educacional, com profissionais altamente qualificados e sempre acompanhados por programas efetivos de formação permanente, a exemplo de países europeus nórdicos (Finlândia é o mais conhecido, por ter ocupado os primeiros lugares no PISA nos 2000, e agora Estônia, por ocupar o posto mais alto na Europa) (DEMO, 2002a). A liderança do PISA, entrementes, migrou para a Ásia, em especial para a China, onde as escolas detêm lugar muito proeminente no desenvolvimento dos países, esperando-se da qualidade da educação básica impacto contundente na competitividade e produtividade econômica. As duas paisagens são apenas aproximativamente comparáveis. São comparáveis no sentido de que a referência econômica é a mais substancial, em última instância, à revelia de discursos pedagógicos piedosos sempre declamados. Mesmo aí, contudo, o sistema asiático de ensino é bem mais violento, em especial na China, que busca, com esforço inaudito na economia e na educação, atingir a liderança mundial (LEE, 2018, MILANOVIC, 2019). Isto tem levado a um endurecimento provocativo do instrucionismo, com reflexos deformadores ostensivos, procedimentos repressivos e 
controladores exacerbados (o suicídio estudantil tem aumentado, por exemplo) (ZHAO, 2014), em especial com respeito ao desempenho em matemática, que países como Finlândia não se dispõem a seguir. O welfare state não é uma maravilha consumada, mas pelo menos preza o bem-estar dos estudantes, que precisam sentir-se bem na escolar, como protagonistas de sua aprendizagem, sem pressões de qualquer ordem, sem ocupar o estudante em demasia (terminado o tempo de escola, os estudantes na Finlândia voltam para casa e não fazem dever de casa, porque é hora da família). Em tom jocoso, Sahlberg fala de "FinishED leadership" (2017) na Finlândia, no eco de um livro anterior em que analisava razões do sucesso finlandês no PISA 2010 (RIPLEY, 2013). Não são comparáveis no sentido de que a rota pedagógica é suficientemente diversa, ou seja, enquanto no mundo asiático questões pedagógicas são de menor ou nenhuma importância (não se perde tempo em discutir formação e outras filosofadas, porque importa a liderança econômica e educacional global), no welfare state deve aparecer o cuidado formativo, ainda que a avaliação se volte ao desempenho técnico apenas. Ambos os ambientes são instrucionistas, porque a instrução direta é o método preconizado básico, voltado para transmissão sistemática e intensa de conteúdo curricular e para a habilidade de buscar resposta certa a questões de preferência fechadas, mas a ambiência pedagógica é bastante mais favorável na Europa.

Em termos pedagógicos, então, a escola se transviou. Sob o peso do instrucionismo voraz e draconiano, sua função se reduz a repassar conteúdo curricular efetivamente, com acento na instrução direta, mantendo-se discursos pedagógicos como enfeite descartável. Paulo Freire não precisa ser expulso da escola, porque não está mais lá (se é que um dia esteve) (DEMO, 2018): o que temos na escola é aula, só aula, repasse de conteúdo, prova para garantir este repasse memorizado. Atividades de aprendizagem não existem, literalmente, nem parecem fazer falta. Em nosso caso, no Enem, candidatos que redigem bem são resíduo ínfimo (por volta de 50 em 4 milhões), pois os cursinhos, instrucionistas desvairados, cuidam de conteúdo memorizado, não da elaboração autoral dos estudantes. A diferença, porém, com o instrucionismo asiático é ingente, porque este ocupa os primeiros lugares do PISA e nós os últimos. Por lá "valem a pena", no sentido pragmático cru de inserção no mercado. Aqui não tem valor. Em termos pedagógicos, contudo, ambos os cenários são deformadores.

No Quadro 1 temos o ranqueamento do PISA 2018 dos países participantes em Leitura (foi o tema básico desta versão), mostrando a liderança das 4 províncias chinesas (proficiência de 555), seguidas de Singapura (549), Macau (525), Hong Kong (524) - até agora são sistemas asiáticos. Aparece então Estônia, o primeiro país europeu no ranking (523, 32 pontos atrás da $1^{a}$ colocação); Canadá vem a seguir (520), junto com Finlândia (520). O Brasil comparece na 
$58^{\text {a }}$ posição (413), sendo o país latino-americano mais bem arrumado o Chile (452), que estava a 39 pontos acima do Brasil.

Quadro 1 - Ranking dos países no PISA 2018 - LEITURA

\begin{tabular}{|c|c|c|c|c|c|c|c|c|c|c|c|}
\hline Países & 13 & & 26 & & 39 & & 52 & & 65 & & 79 \\
\hline $\begin{array}{l}\text { PXJG } \\
\text { (China)* }\end{array}$ & $\begin{array}{l}55 \\
5\end{array}$ & Vietnã & $\begin{array}{l}50 \\
5\end{array}$ & Holanda & $\begin{array}{l}48 \\
5\end{array}$ & Ucrânia & $\begin{array}{l}46 \\
6\end{array}$ & $\begin{array}{l}\text { Montenegr } \\
\text { o }\end{array}$ & $\begin{array}{l}42 \\
1\end{array}$ & Ar. Saudita & 399 \\
\hline Singapura & $\begin{array}{l}54 \\
9\end{array}$ & $\begin{array}{l}\text { Reino } \\
\text { Unido }\end{array}$ & $\begin{array}{l}50 \\
4\end{array}$ & Áustria & $\begin{array}{l}48 \\
4\end{array}$ & Turquia & $\begin{array}{l}46 \\
6\end{array}$ & México & $\begin{array}{l}42 \\
0\end{array}$ & Tailândia & 393 \\
\hline $\begin{array}{l}\text { Macau } \\
\text { (China) }\end{array}$ & $\begin{array}{l}52 \\
5\end{array}$ & Japão & $\begin{array}{l}50 \\
4\end{array}$ & Suíça & $\begin{array}{l}48 \\
4\end{array}$ & $\begin{array}{l}\text { Eslováqu } \\
\text { ia }\end{array}$ & $\begin{array}{l}45 \\
8\end{array}$ & Bulgária & $\begin{array}{l}42 \\
0\end{array}$ & $\begin{array}{l}\text { Maced. do } \\
\text { Norte }\end{array}$ & 393 \\
\hline $\begin{array}{l}\text { Hong Kong } \\
\text { (Ch.) }\end{array}$ & $\begin{array}{l}52 \\
4\end{array}$ & Austrália & $\begin{array}{l}50 \\
3\end{array}$ & Croácia & $\begin{array}{l}47 \\
9\end{array}$ & Grécia & $\begin{array}{l}45 \\
7\end{array}$ & Jordânia & $\begin{array}{l}41 \\
9\end{array}$ & $\begin{array}{l}\text { Baku } \\
\text { (Azerbaijão) }\end{array}$ & 389 \\
\hline Estônia & $\begin{array}{l}52 \\
3\end{array}$ & $\begin{array}{l}\text { Taipei } \\
\text { (Ch.) }\end{array}$ & $\begin{array}{l}50 \\
3\end{array}$ & Letônia & $\begin{array}{l}47 \\
9\end{array}$ & Chile & $\begin{array}{l}45 \\
2\end{array}$ & Malásia & $\begin{array}{l}41 \\
5\end{array}$ & Cazaquistão & 387 \\
\hline Canadá & $\begin{array}{l}52 \\
0\end{array}$ & Dinamarca & $\begin{array}{l}50 \\
1\end{array}$ & Rússia & $\begin{array}{l}47 \\
9\end{array}$ & Malta & $\begin{array}{l}44 \\
8\end{array}$ & Brasil (58) & $\begin{array}{l}41 \\
3\end{array}$ & Geórgia & 380 \\
\hline Finlândia & $\begin{array}{l}52 \\
0\end{array}$ & Noruega & $\begin{array}{l}49 \\
9\end{array}$ & Itália & $\begin{array}{l}47 \\
6\end{array}$ & Sérvia & $\begin{array}{l}43 \\
9\end{array}$ & Colômbia & $\begin{array}{l}41 \\
2\end{array}$ & Panamá & 377 \\
\hline Irlanda & $\begin{array}{l}51 \\
8\end{array}$ & Alemanha & $\begin{array}{l}49 \\
8\end{array}$ & Hungria & $\begin{array}{l}47 \\
6\end{array}$ & $\begin{array}{l}\text { Em. Ár. } \\
\text { Un. }\end{array}$ & $\begin{array}{l}43 \\
2\end{array}$ & Brunei & $\begin{array}{l}40 \\
8\end{array}$ & Indonésia & 371 \\
\hline Coreia & $\begin{array}{l}51 \\
4\end{array}$ & Eslovênia & $\begin{array}{l}49 \\
5\end{array}$ & Lituânia & $\begin{array}{l}47 \\
6\end{array}$ & Romênia & $\begin{array}{l}42 \\
8\end{array}$ & Catar & $\begin{array}{l}40 \\
7\end{array}$ & Marrocos & 359 \\
\hline Polônia & $\begin{array}{l}51 \\
2\end{array}$ & Bélgica & $\begin{array}{l}49 \\
3\end{array}$ & Islândia & $\begin{array}{l}47 \\
4\end{array}$ & Uruguai & $\begin{array}{l}42 \\
7\end{array}$ & Albânia & $\begin{array}{l}40 \\
5\end{array}$ & Líbano & 353 \\
\hline Suécia & $\begin{array}{l}50 \\
6\end{array}$ & França & $\begin{array}{l}49 \\
3\end{array}$ & $\begin{array}{l}\text { Bielorrús } \\
\text { sia }\end{array}$ & $\begin{array}{l}47 \\
4\end{array}$ & $\begin{array}{l}\text { Costa } \\
\text { Rica }\end{array}$ & $\begin{array}{l}42 \\
6\end{array}$ & $\begin{array}{l}\text { Bósn./Herz } \\
\text { eg. }\end{array}$ & $\begin{array}{l}40 \\
3\end{array}$ & Kosovo & 353 \\
\hline $\begin{array}{l}\text { Nova } \\
\text { Zelândia }\end{array}$ & $\begin{array}{l}50 \\
6\end{array}$ & Portugal & $\begin{array}{l}49 \\
2\end{array}$ & Israel & $\begin{array}{l}47 \\
0\end{array}$ & Chipre & $\begin{array}{l}42 \\
4\end{array}$ & Argentina & $\begin{array}{l}40 \\
2\end{array}$ & Rep. Domin. & 342 \\
\hline $\begin{array}{l}\text { Estados } \\
\text { Unidos }\end{array}$ & $\begin{array}{l}50 \\
5\end{array}$ & $\begin{array}{l}\text { Rep. } \\
\text { Tcheca }\end{array}$ & $\begin{array}{l}49 \\
0\end{array}$ & $\begin{array}{l}\text { Luxembu } \\
\text { rgo }\end{array}$ & $\begin{array}{l}47 \\
0\end{array}$ & Moldávia & $\begin{array}{l}42 \\
4\end{array}$ & Peru & $\begin{array}{l}40 \\
1\end{array}$ & Filipinas & 340 \\
\hline & & & & & & & & & & Espanha & $\begin{array}{l}\mathrm{m}^{*} \\
*\end{array}$ \\
\hline
\end{tabular}

*Pequim, Xangai, Jiangsu, Guangdong.

**Dados anômalos.

Fonte: Demo (2020a)

Os Estados Unidos estavam na $13^{\mathrm{a}}$ posição (505), 50 pontos atrás da primeira posição chinesa, o que sugere uma distância preocupante que não combina com a posição global do país. Nos dois últimos lugares estavam Filipinas (340, por sinal asiático, mas de colonização espanhola) e República Dominicana (342), a uma distância astronômica do $1^{\circ}$ lugar chinês (215 pontos para com Filipinas, 213 para com República Dominicana). No quadro, a escola pública 
não está separada, mas como é, em geral, a oferta dominante (no Brasil, 80\%), os dados insinuam ostensivamente desempenhos muito insuficientes como regra geral. Usando de rigor, digamos que o desempenho mais satisfatório se constata em apenas 10 países (até Polônia, com 512 de proficiência em leitura), sendo que cinco são asiáticos e na liderança (com exceção da Coreia). Se nos perguntássemos como e quando países como República Dominicana e Filipinas, mas também o Brasil, poderiam ter o desempenho chinês, postulando não imitar o instrucionismo truculento, por certo? De um lado, o êxito chinês, também o coreano, indicam que é possível arrumar a casa, mesmo no instrucionismo mais devastador (RIPLEY, 2013), mas o atraso na outra ponta sugere que tais feitos são quase excepcionais. Enquanto a escola numa ponta é efetiva, mesmo tão deformadora, na outra é uma inutilidade.

No Quadro 2 aprece o desempenho em matemática, que eleva sobremaneira o contraste e a angústia. A primeira observação é o feito chinês (mesmo restrito a 4 províncias), bem acima do segundo país (Singapura: 591 x 569; distância de 22 pontos em proficiência). Países asiáticos ocupam os 7 primeiros lugares, aparecendo Estônia em $8^{\circ}$. Esta condição insinua que êxito matemático vai virando feito asiático, sobretudo chinês. Os Estados Unidos, no $13^{\circ}$ lugar em leitura, agora ocupam o $38^{\circ}$ lugar, um vexame contundente. O Brasil aparece no $71^{\circ}$ lugar, enquanto Uruguai no $59^{\circ}$ e o Chile no $60^{\circ}$. Nos dois últimos lugares temos, de novo, um país asiático, Filipinas (353) e um latino-americano e caribenho, República Dominicana (325), a anos-luz do primeiro lugar chinês: 238 e 266 de distância respectivamente.

Quadro 2 - Ranking dos países no PISA 2018 - MATEMÁTICA

\begin{tabular}{|c|c|c|c|c|c|c|c|c|c|c|c|}
\hline Países & 13 & & 26 & & 39 & & 52 & & 65 & & 79 \\
\hline $\begin{array}{l}\text { PXJG } \\
\text { (China)* }\end{array}$ & 591 & Eslovênia & 509 & Islândia & 495 & Malta & 472 & Romênia & 430 & Jordânia & 400 \\
\hline Cingapura & 569 & Bélgica & 508 & Nova Zel. & 494 & Croácia & 464 & Montenegro & 430 & Geórgia & 398 \\
\hline $\begin{array}{l}\text { Macau } \\
\text { (China) }\end{array}$ & 558 & Finlândia & 507 & Portugal & 492 & Israel & 463 & Cazaquistão & 423 & $\begin{array}{l}\text { Maced. do } \\
\text { Norte }\end{array}$ & 394 \\
\hline $\begin{array}{l}\text { H. Kong } \\
\text { (Ch.) }\end{array}$ & 551 & Suécia & 502 & Austrália & 491 & Turquia & 454 & Moldávia & 421 & Líbano & 393 \\
\hline $\begin{array}{l}\text { Taipei } \\
\text { (Ch.) }\end{array}$ & 531 & $\begin{array}{l}\text { Reino } \\
\text { Unido }\end{array}$ & 502 & Rússia & 488 & Ucrânia & 453 & $\begin{array}{l}\text { Baku } \\
\text { (Azerbaijão) }\end{array}$ & 420 & Colômbia & 391 \\
\hline Japão & 527 & Noruega & 501 & Itália & 487 & Grécia & 451 & Tailândia & 419 & $\begin{array}{l}\text { Brasil } \\
\text { (71) }\end{array}$ & 384 \\
\hline Coreia & 526 & Alemanha & 500 & Eslováquia & 486 & Chipre & 451 & Uruguai & 418 & Argentina & 379 \\
\hline Estônia & 523 & Irlanda & 500 & Luxemburgo & 483 & Sérvia & 448 & Chile & 417 & Indonésia & 379 \\
\hline Holanda & 519 & $\begin{array}{l}\text { Rep. } \\
\text { Tcheca }\end{array}$ & 499 & Espanha & 481 & Malásia & 440 & Catar & 414 & $\begin{array}{l}\text { Ar. } \\
\text { Saudita }\end{array}$ & 373 \\
\hline
\end{tabular}




\begin{tabular}{|l|l||l|l||l|l||l|l||l|l||l|l||}
\hline Polônia & 516 & Áustria & 499 & Lituânia & 481 & Albânia & 437 & México & 409 & Marrocos & 368 \\
\hline Suíça & 515 & Letônia & 496 & Hungria & 481 & Bulgária & 436 & Bósn./Herzeg. & 406 & Kosovo & 366 \\
\hline Canadá & 512 & Vietnã & 496 & Est. Unidos & 478 & $\begin{array}{l}\text { Em. Ár. } \\
\text { Un. }\end{array}$ & 435 & Costa Rica & 402 & Panamá & 353 \\
\hline Dinamarca & 509 & França & 495 & Bielorrússia & 472 & Brunei & 430 & Peru & 400 & Filipinas & 353 \\
\hline \hline & & & & & & & & & & Rep. \\
Domin.
\end{tabular}

*Pequim, Xangai, Jiangsu, Guangdong.

Fonte: Demo (2020a)

Como e quando a República Dominicana poderia ter o desempenho chinês?

Podemos observar neste repto duas incongruências doloridas. Primeiro, vale a pena rivalizar com a China, se o sistema de ensino é tão deformador? Segundo, para ter desempenho similar e, sobretudo, alternativo na dimensão pedagógica, teríamos de mudar tudo. A comparação, por suposto, precisa ser feita com sabedoria, porque comparamos histórias e condições muito diversas: são República Dominicana e China situações comparáveis? Certamente, podemos comparar, mesmo que isto exija forçar a barra, mas é uma violência. Esta ponderação não refresca, porém, que o desempenho na maioria dos países em matemática é uma miséria sem fim, tornando-se exercício pouco útil filosofar sobre como ocupar um dia o $1^{\circ}$ lugar no PISA.

Incomodam nesse quadro dois tópicos basilares. Num lado, que os dois primeiros lugares sejam ocupados por países extremamente instrucionistas (sem falar que China e Singapura são regimes ditatoriais); noutro, que não são bons exemplos pedagógicos; ao contrário.

\section{Escola pública e privada no Brasil}

A escola privada no Brasil, que atende por volta de $20 \%$ dos estudantes, está, em geral, 2 pontos inteiros acima do desempenho da escola pública, como se aprecia no Quadro 3. Vemos que a escola privada não atingiu a meta de 2017 em nenhum caso (Anos Iniciais, Anos Finais, Ensino Médio), enquanto a escola pública somente nos Anos Iniciais. Tomando a referência do Ensino Médio, a proficiência em 2005 foi de 5.6, empacando nesse patamar alguns períodos, e descendo para 5.3 em 2016; em 2017 chegou a 5.8, pouco acima do nível de 2005. Sob tais cifras, a escola privada parece ser um sistema bem estagnado. 
Quadro 3 - Ideb (Proficiência) 2005-2017 - Brasil

\begin{tabular}{|c|c|c|c|c|c|c|c|c||}
\hline & 2005 & 2007 & 2009 & 2011 & 2013 & 2015 & 2017 & Meta 2017 \\
\hline \hline \multicolumn{7}{|c||}{ Anos Iniciais } \\
\hline Privada & 5,9 & 6,0 & 6,4 & 6,5 & 6,7 & 6,8 & 7,1 & 7,2 \\
\hline Pública & 3,6 & 4,0 & 4,4 & 4,7 & 4,9 & 5,3 & 5,5 & 5,2 \\
\hline \hline \multicolumn{7}{|c|}{ Anos Finais } \\
\hline Privada & 5,8 & 5,8 & 5,9 & 6,0 & 5,9 & 6,1 & 6,4 & 7,0 \\
\hline Pública & 3,2 & 3,5 & 3,7 & 3,9 & 4,0 & 4,2 & 4,4 & 4,7 \\
\hline \hline & & & & & & \\
\hline Privada & 5,6 & 5,6 & 5,6 & 5,7 & 5,4 & 5,3 & 5,8 & 6,7 \\
\hline Pública & 3,1 & 3,2 & 3,4 & 3,4 & 3,4 & 3,5 & 3,5 & 4,4 \\
\hline
\end{tabular}

Fonte: INEP

Esta impressão é muito reforçada no Quadro 4, onde se comparam as grandes regiões, cujos números de 2017 são praticamente os mesmos de 2005. Como é a escola considerada modelo de êxito escolar, em especial porque abre as portas das melhores universidades públicas gratuitas, parece não estar incomodada com a estagnação pedagógica. Os próprios louros atrapalham, assim como o êxito pode ser o inimigo da mudança/inovação e da aprendizagem (CHRISTENSEN, 2011).

Quadro 4 - Ideb (Proficiência) das Escolas Privadas nas Regiões, 2005-2017

\begin{tabular}{|l|c|c|c|c|c|c|c||}
\hline & 2005 & 2007 & 2009 & 2011 & 2013 & 2015 & 2017 \\
\hline \hline Brasil & 5,6 & 5,6 & 5,6 & 5,7 & 5,4 & 5,3 & 5,8 \\
\hline Norte & 5,0 & 5,1 & 5,4 & 5,2 & 5,0 & 4,7 & 5,5 \\
\hline Nordeste & 5,2 & 5,1 & 5,2 & 5,4 & 5,2 & 5,1 & 5,5 \\
\hline Sudeste & 5,7 & 5,7 & 5,6 & 5,8 & 5,4 & 5,5 & 5,9 \\
\hline Sul & 5,9 & 5,8 & 5,9 & 6,0 & 5,7 & 5,6 & 5,9 \\
\hline $\begin{array}{l}\text { Centro- } \\
\text { Oeste }\end{array}$ & 5,7 & 5,5 & 5,8 & 5,6 & 5,6 & 5,4 & 5,7 \\
\hline
\end{tabular}

Fonte: INEP

Observando mais atentamente, a diferença de dois pontos não é pedagógica. Embora seja marcante e por esta razão, quem pode, coloca o filho na escola privada, o ganho é instrucionista, ao estilo asiático, buscado via disciplina, controle, gestão severa, pressão dos pais etc. Mas, como é o êxito que importa, em termos de abrir chances do melhor curso universitário gratuito, tornou-se crendice comum que a escola privada seria pedagogicamente melhor. Na média, não é, também porque trabalha com os mesmos professores, oferece a 
mesma aula (conteudista sem meios termos), pratica a mesma avaliação, aposta em instrução direta ostensivamente. A escola pública tem, sim algo a aprender da escola privada, em especial disciplina e gestão, desde que se tenha em mente que isto não garante a qualidade pedagógica (LUBIENSKI; LUBIENSKI, 2013).

Dito isto, é absolutamente importante frisar o papel da escola pública, não só porque atinge a $80 \%$ dos estudantes, mas porque é a via de inserção sociocultural e econômica possível para eles, praticamente a única. Os dados disponíveis, mesmo muito questionáveis, indicam desempenho extremamente pífio na escola brasileira, como marca geral, e mais acentuado ainda em regiões menos desenvolvidas. Por exemplo no Norte e Nordeste, o aprendizado adequado de matemática, desde 1995 (quando começa a série histórica do Ideb) está por volta dos 5\% ou menos, sem perspectiva de melhora efetiva. Apenas para exemplificar, observemos os dados do Pará, o estado mais distinguido do Norte em termos socioculturais. Nos Anos Iniciais, o aprendizado adequado de matemática em 2017 foi de 23.1\% (não chegou a 1/4), embora tenha subido bastante em relação a 1995 (5.9\%); em língua portuguesa, chegou a 37.5\% em 2017, pouco mais de 1/3; em relação a 1995, quando teve a cifra de $30.7 \%$, ao aumento em 22 anos foi clamorosamente restrito.

Quadro 5 - Pará - Aprendizado adequado, 1995-2017 - Ideb (\%)

\begin{tabular}{|r|r|r|r|r|r|r|r|r|r|r|r|r||}
\hline Anos & 1995 & 1997 & 1999 & 2001 & 2003 & 2005 & 2007 & 2009 & 2011 & 2013 & 2015 & 2017 \\
\hline \hline $5^{\text {o }}$ - EF - Matemática & 05.9 & 07.9 & 08.0 & 06.0 & 05.4 & 05.5 & 10.9 & - & 18.0 & 17.4 & 22.1 & 23.1 \\
\hline $5^{\circ}-$ EF - L. Portuguesa & 30.7 & 20.6 & 13.2 & 15.2 & 14.7 & 17.5 & 15.4 & - & 26.4 & 25.5 & 37.0 & 37.5 \\
\hline \hline $9^{\text {o }}$ - EF - Matemática & 06.1 & 07.0 & 04.2 & 06.5 & 05.3 & 05.2 & 06.6 & - & 08.6 & 07.7 & 07.9 & 08.3 \\
\hline $9^{\text {o }}$ - EF - L. Portuguesa & 29.3 & 25.8 & 15.1 & 18.4 & 13.4 & 13.8 & 13.0 & - & 19.4 & 21.0 & 23.6 & 23.2 \\
\hline \hline $3^{\text {o }}$ EM - Matemática & 04.3 & 06.5 & 03.1 & 05.4 & 04.6 & 04.1 & 03.1 & - & 04.5 & 03.5 & 02.9 & 03.9 \\
\hline $3^{\text {o }}$ Em - L. Portuguesa & 32.4 & 37.9 & 12.9 & 19.3 & 16.0 & 14.2 & 13.3 & - & 26.1 & 14.8 & 19.0 & 15.6 \\
\hline
\end{tabular}

Fonte: Inep/Todos pela Educação

Nos Anos Finais, o aprendizado adequado em matemática foi de 6.1\% em 1995 e de 8.3\% em 2017, em estagnação ostensiva, além de a cifra ser precaríssima. Em língua portuguesa, a cifra foi de $29.3 \%$ em 1995, e de 23.2\% em 2017, andando para trás, inacreditavelmente. No Ensino Médio, o aprendizado adequado em matemática foi de $4.3 \%$ em 1995 e de 3.9\% em 2017, indicando inépcia total do sistema de ensino. Em língua portuguesa, começou com 32.4\% em 1995, mas a cifra era de 15.6\% em 2017, a metade da inicial, uma situação de recuo totalmente irresponsável. Literalmente, matemática não existe, não só no EM, onde é regra não existir; não existe também nos Anos Finais, e mesmo nos Anos Iniciais. Em língua portuguesa, nos Anos Iniciais o avanço em 22 anos foi insignificante, sendo que houve recuo acentuado nos Anos Finais e sobretudo no Ensino Médio. Parece claro que a escola 
básica, na média, é uma instituição falida. Qual o sentido de ser obrigado a frequentar uma escola onde 3.9\% dos estudantes aprendem matemática no Ensino Médio? O constrangimento é ainda maior quando se nota não haver sinais de melhora, indicando que a miséria se tornou padrão.

Esta situação nos leva a refletir sobre nossa impotência em oferecer à população a educação de que precisa para poder ter alguma chance na vida. Temos a instituição formal, gastamos recursos, erigimos instituições físicas (escolas), temos profissionais qualificados (professores), temos todas as aulas, mas não temos aprendizagem. Os governos mudam, inclusive tivemos dois mais à esquerda recentemente (Lula e Dilma), mas o instrucionismo parece ser a sina de todos. Pior que isso, muitos educadores que se querem ou imaginam de esquerda insistem no mesmo instrucionismo que sufoca a escola, defendem o sistema de ensino ferrenhamente, e com isto acabam defendendo a exclusão crua dos estudantes, evitando diagnosticar, para não termos de encarar que precisamos mudar radicalmente.

Ocorre que mudar a escola é uma empreitada astronômica. Quando ligamos a escola à democracia, em geral esquecemos que uma puxa a outra: se precisamos de boa escola para termos boa democracia, precisamos de boa democracia, para termos boa escola. Os resultados escolares lançam uma luz duvidosa sobre a formação docente, embora não se possa falar de culpa, mas precisamos falar de má formação inicial e continuada. Professores não são profissionais da aprendizagem, mas do ensino. Não sendo autores, cientistas, pesquisadores, consideram sua função repassar conteúdos, o que apenas reforça que, quem não sabe aprender, não pode cuidar da aprendizagem de outrem. Na prática, nunca tomamos os professores a sério, mesmo quando inventamos um piso salarial, por sinal infame. As licenciaturas são precaríssimas, quase inúteis. A pedagogia rasa, não estando à altura do desafio da alfabetização. Inventamos uma engrenagem enorme que funciona motu proprio e inutilmente. Os alunos frequentam a escola inutilmente. 


\section{A quem interessa?}

Segundo o INAF (Indicador de Alfabetismo Funcional) (2018) (Quadro 6), apenas 12\% dos adultos seriam "proficientes" (digamos, sabem pensar). Analfabetos tradicionais seriam ainda $8 \%$, mas analfabetos funcionais chegam a 30\%. Mesmo entre quem tem educação superior, apenas $34 \%$ seriam proficientes.

Quadro 6 - Distribuição da população por níveis de Alfabetismo e Escolaridade - 2018

\begin{tabular}{|c||c|c|c||c||c|c||}
\hline & Total & Nenhuma & $\begin{array}{c}\text { Ens. Fund. - Anos } \\
\text { Iniciais }\end{array}$ & $\begin{array}{c}\text { Ens. Fund. - Anos } \\
\text { Finais }\end{array}$ & $\begin{array}{c}\text { Ensino } \\
\text { Médio }\end{array}$ & Superior \\
\hline \hline Base & 2002 & 116 & 297 & 451 & 796 & 342 \\
\hline \hline Analfabeto & $8 \%$ & $82 \%$ & $16 \%$ & $1 \%$ & $1 \%$ & $0 \%$ \\
\hline Rudimentar & $22 \%$ & $17 \%$ & $54 \%$ & $32 \%$ & $12 \%$ & $4 \%$ \\
\hline Elementar & $34 \%$ & $0 \%$ & $21 \%$ & $45 \%$ & $42 \%$ & $25 \%$ \\
\hline Intermediário & $25 \%$ & $1 \%$ & $7 \%$ & $17 \%$ & $33 \%$ & $37 \%$ \\
\hline Proficiente & $12 \%$ & $0 \%$ & $1 \%$ & $4 \%$ & $12 \%$ & $34 \%$ \\
\hline \hline Total & 100 & 100 & 100 & 100 & 100 & 100 \\
\hline \hline Analfabetos funcionais & $29 \%$ & $99 \%$ & $70 \%$ & $34 \%$ & $13 \%$ & $4 \%$ \\
\hline Funcionalmente & $71 \%$ & $1 \%$ & $29 \%$ & $66 \%$ & $87 \%$ & $96 \%$ \\
alfabetizados & & & & & & \\
\hline
\end{tabular}

Fonte: INAF (2018)

O Quadro desvela o que resta da escola para nossas vidas (DEMO, 2020b): quase nada. Só no tempo de Ensino Fundamental e Médio são 12 anos, para a grande maioria, jogados fora. Trata-se de uma miséria lancinante, humilhante. A quem interessa?

Tomando em conta a questão da pobreza política (DEMO, 2007), a imbecilização popular interessa politicamente, porque é manobra de acesso e permanência no poder o voto de cabresto, o curral eleitoral, os clientelismos assistencialistas e assim por diante. Aí entra o valor de uma escola pública de qualidade: se tivesse impacto no processo eleitoral via formação da consciência crítica na escola, já seria contribuição inestimável para a qualificação da democracia. Embora não se possam interpor acertos lineares entre um lado e outro, pessoas mais bem educadas podem mais facilmente reagir à corrupção política, discutir candidatos, candidaturas, partidos políticos, políticas sociais e econômicas, igualitarismo social etc. Sem desconhecer o impacto das Grandes Guerras na reestruturação mais igualitária das sociedades, o fato de que a educação primária já estava devidamente universalizada teve contribuição decisiva, também para a sindicalização, a formação partidária, as instituições democráticas. A ideia de que pelo menos metade da população precisa estar no meio da pirâmide só medra se 
houver eco na população que sabe apreciar este resultado como direito fundamental. As mulheres, facilmente coibidas de votar e estudar, são exemplo vívido de como a alfabetização e a escolarização com alguma qualidade despertou as energias femininas, a ponto de hoje ser possível, mesmo ainda seletivamente, construir condições igualitárias de gênero. Este é exemplo talvez mais pertinente: as meninas hoje não só têm melhor desempenho escolar que os meninos, estão avançando em áreas estratégicas acadêmicas, como da saúde e, nesta, em especial, da medicina, indicando uma possível virada.

Cabe, porém, reconhecer que já não interessa o atraso economicamente, porque competitividade e produtividade exigem preparo acadêmico. Tomando quiçá o exemplo mais gritante, profissões digitais mais elevadas, como programação e analítica digital, supõem formação esmerada em matemática. Neste sentido, a calamidade matemática de nossa escola está totalmente na contramão. É um desacerto medonho condenar grandes maiorias ao trabalho informal, ao salário mínimo, à inclusão marginal, porque isto não permite participar do capitalismo global de modo minimamente adequado. A sina será viver de uma economia improdutiva e informal, incapaz de competir no mercado, deixando para trás maiorias laborais. Este argumento é hoje incontornável: num tipo de economia o Brasil é competitivo - no agronegócio; resultado, compete bem globalmente. Precisamos então distinguir as coisas. No plano político, imbecilizar as pessoas ainda é estratégia política de acesso e permanência no poder. Na economia, não mais. Na economia fordista, o trabalhador, condenado a tarefas apenas repetitivas, não precisa educar-se. No capitalismo cognitivo, virou contrassenso (WORLD BANK, 2018).

A questão, porém, não cessa aí. Prenuncia-se no horizonte que avanços na tecnologia digital, em especial da analítica digital, vão encurralar o trabalho humano, talvez não restando quase nada mais a fazer, mesmo em esferas muito intelectualizadas (WORLD BANK, 2018a; 2019). Se trabalho humano vier a reduzir-se a mínimos ou a nada, o cenário muda totalmente de contorno. A grande maioria terá de viver de renda de cidadania ou algo parecido, levando a repensar dramaticamente democracia e república, em especial a economia (DEMO, 2020c). Esta condição, no entanto, se vier a ocorrer, vai exigir formação ainda mais acurada do trabalhador, tendo vista a diminuição drástica do espectro de escolha profissional. Na prática, antes disso, a conturbação maior é não haver trabalho, não só porque a economia se digitalizou velozmente, mas simplesmente porque não tem dinamismo para produzir empregos formais: a informalidade vai comandar a cena... Podemos chegar a um ponto no qual estudar já não rende, porque não há trabalho para quem estudou, ou, o emprego encontrado não consegue gerar o suficiente para pagar a dívida estudantil. 
Um dos maiores sarcasmos da escola pública é a crendice de que frequentá-la basta. Comparecer todo dia às aulas é condição suficiente. Podemos ver essa fatuidade no Bolsa Família, quando se condiciona a bolsa à frequência escolar dos filhos. É uma exigência pleonástica, pois já é constitucional. Não se quer ver, porém, que frequentar grande parte das escolas não tem efeito nenhum, a não ser em externalidades pertinentes como da socialização das crianças, da merenda, da guarda. Dizia Werneck provocativamente: "Se você finge que ensina, eu finjo que aprendo" (1993).

O IDH, por sua vez, avalia educação por "anos de escolarização", uma medida inútil. Como a escola está devastada pela "progressão automática" - avança-se sem aprender - os anos de estudo não somam mais. Não se trata de propor a reprovação, porque não é finalidade da escola excluir estudante. Mas é direito do estudante avançar aprendendo. Avançar sem aprender é um golpe baixo. Ao fim do EM, o estudante se dá conta de que os 12 anos de estudo que deveria ter por conta de ter frequentado o EF e o EM são farsantes, vazios, inúteis. Quando ensino substitui aprendizagem, é porque cuidamos do formalismo instrucionista, não dos estudantes.

\section{Considerações finais}

Escola pública é um tesouro depredado. Ao mesmo tempo, serve de indicador da capacidade de cada país de arquitetar um projeto coletivo de desenvolvimento, no qual caibam todos. Políticas educacionais estão, tipicamente, entre as mais farsantes (faz-de-conta) vigentes, a nível de fraudes oficializadas. Não conseguimos aprender sequer a regra mínima (minimalista) do welfare state capitalista da inclusão majoritária: um país só é viável, se pelo menos a maioria estiver incluída no meio da pirâmide socioeconômica. Esta regra não é suficiente, porque não chega devidamente a resguardar qualidade de vida; vai até à quantidade de vida. A questão do salário mínimo é exemplar: primeiro, define a Constituição um salário mínimo, cujo valor real está 4 vezes abaixo da definição formal; segundo, cada ano, ao invés de empurrar um aumento real, para podermos nos aproximar da definição formal, o reajustamos apenas conforme a inflação, postulando que o sistema não consegue arcar com os custos, mas à população não resta saída, senão aceitar subservientemente. Assim, maiorias são incluídas na margem, jamais no meio. Uma economia que não consegue pagar o mínimo constitucional real ainda não é "uma economia", é apenas um arremedo e só confirma a praga liberal: o mercado não é instrumento da sociedade; é ao contrário. 
Escola pública temos em toda parte, onde estudam $80 \%$ dos estudantes. A situação típica é de precariedade física, equipamentos insuficientes, incompletos, inexistentes; precariedade flagrante em termos didáticos (laboratórios, materiais didáticos, ambientes escolares); salas cheias; sobretudo aproveitamento dantesco (ANUÁRIO BRASILEIRO DA EDUCAÇÃO BÁSICA, 2019). Escola pública não é lugar de honra, é um logradouro obrigatório que se engole à força. É parte das "coisas públicas" de democracias fajutas, e por isso é depredada facilmente, feia, pichada, murada, prisional. Tem a cara de nossa democracia.

\section{REFERÊNCIAS}

\section{ANUÁRIO BRASILEIRO DA EDUCAÇÃO BÁSICA 2019. Todos pela}

Educação/Moderna. São Paulo. Disponível em:

https://www.todospelaeducacao.org.br/_uploads/_posts/302.pdf. Acesso em: 20 set. 2020

CHRISTENSEN, C. M. The innovator's dilemma: the revolutionary book that will change the way you do business. Harper Business, 2011.

DEMO, P. Pobreza política. A pobreza mais intensa da pobreza brasileira. Campinas, SP: Autores Associados, 2007

DEMO, P. Sucesso educacional em questão. Supremacia asiática educacional questionada. 2020. Disponível em: https://pedrodemo.blogspot.com/2020/08/ensaio-532sucesso-educacional-em_25.html. Acesso em: 20 set. 2020.

DEMO, P. Educação à Deriva. À direita e à esquerda: instrucionismo como patrimônio nacional. 2020a. Disponível em: https:/drive.google.com/file/d/10nMlgL8N9GKFgwtnbLbIn7GQf0HdyA4/view. Acesso em: 20 set. 2020.

DEMO, P. O que resta da escola na vida. 2020b. Disponível em: https://drive.google.com/file/d/1swMQ-4m1DKJ4Nhfa_CbxrR4upYKZLPBG/view. Acesso em: 20 set. 2020.

DEMO, P. Renda básica. 2020c. Disponível em: https://drive.google.com/file/d/1y6VdrxfgsUQ2Fbwx-QiQyfdlBMAutVcJ/view. Acesso em: 20 set. 2020.

FOUCAULT, M. Vigiar e punir. História da violência nas prisões. Petrópolis: Vozes, 1977.

FREIRE, P. A Importância do ato de ler. São Paulo: Cortez, 1989. Disponível em: http://educacaointegral.org.br/wp-content/uploads/2014/10/importancia_ato_ler.pdf. Acesso em: 20 set. 2020.

FUMAGALLI, A.; GIULIANI, A.; LUCARELLI, S.; VERCELLONE, C. Cognitive capitalism, welfare and labor: the commonfare hypothesis. Routledge, 2019. 
INAF. Indicador de Alfabetismo Funcional. Instituto Paulo Montenegro. Ação Educativa. São Paulo, 2018.

LEE, K-F. AI Superpowers: China, Silicon Valley, and the new world order. N.Y.: Houghton Mifflin Harcourt, 2018.

LUBIENSKI, C. A.; LUBIENSKI, S. T. The public school advantage: why public schools outperform private schools. Chicago: University of Chicago Press, 2013.

MANGUEL, A. Uma história da leitura. São Paulo: Companhia das Letras, 1996.

MEZIROW, J. Learning as transformation. Critical perspectives on a theory in progress. San Francisco: Jossey-Bass, 2000.

MEZIROW, J.; TAYLOR, E. W. Transformative learning in practice: insights from community, workplace, and higher education. London: Jossey Bass, 2009.

MEZIROW, J. Learning as transformation. San Francisco: Jossey-Bass, 2000.

MILANOVIC, B. Capitalism, alone. The future of the system that rules the world. Harvard U. Press, 2019.

PIKETTY, T. Capital and Ideology. Harvard U. Press, 2020.

RINDERMANN, H. Cognitive capitalism. Human capital and the wellbeing of nations. Cambridge U. Press, 2018.

RIPLEY, A. The smartest kids in the world: and how they got that way. N.Y.: Simon \& Schuster, 2013.

SAHLBERG, P. Finnish lessons. What can the world learn from educational change in Finland? N.Y.: Teachers College, 2010.

SAHLBERG, P. FinishED leadership. Thousand Oaks: Corwin, 2017.

SEVERINO, A. J. Pesquisa educacional: da consistência epistemológica ao compromisso ético. Revista Ibero-Americana de Estudos em Educação, Araraquara, v. 14, n. 3, p. 900-916, 2019. DOI: 10.21723/riaee.v14i3.12445. Disponível em: https://periodicos.fclar.unesp.br/iberoamericana/article/view/12445. Acesso em: $28 \mathrm{dez}$. 2019.

TAYLOR, E. W.; CRANTON, P. The handbook of transformative learning. Theory, research, and practice. San Francisco: Jossey-Bass, 2012.

WERNECK, H. Se você finge que ensina, eu finjo que aprendo. Petrópolis: Vozes, 1993.

WORLD BANK (WB). Learning: to realize education's promise. Washington: The World Bank, 2018. Disponível em: https://openknowledge.worldbank.org/handle/10986/28340. Acesso em: 20 set. 2020. 
WORLD BANK (WB). Poverty and shared prosperity 2018: piecing together the poverty puzzle. Washington: The World Bank, 2018a. Disponível em:

https://openknowledge.worldbank.org/bitstream/handle/10986/30418/9781464813306.pdf. Acesso em 20 set. 2020.

WORLD BANK (WB). The Changing Nature of Work. Washington: The World Bank, 2019. Disponível em:

http://documents.worldbank.org/curated/en/816281518818814423/pdf/2019-WDR-

Report.pdf. Acesso em: 20 set. 2020.

ZHAO, Y. Who is afraid of the big bad dragon: why China has the best (and the worst) education system in the world? San Francisco: Jossey-Bass, 2014.

ZHAO, Y. What works may hurt. Side effects in education. Teachers College Press, 2018.

ZHAO, Y.; EMLER, T. E.; SNETHEN, A.; YIN, D. An education crisis is a terrible thing to waste. How radical changes can spark student excitement and success. Teachers College Press, 2019. 


\section{Como referenciar este artigo}

DEMO, P.; SILVA, R. A. Obviedades não óbvias da educação: escola pública. Doxa: Rev. Bras. Psico. e Educ., Araraquara, v. 22, n. 2, p. 424-441, jul./dez. 2020. e-ISSN: 2594-8385. DOI: https://doi.org/10.30715/doxa.v22i2.14209

Submetido em: 20/03/2020

Revisões requeridas: $30 / 06 / 2020$

Aprovado em: 07/08/2020

Publicado em: $31 / 08 / 2020$ 